\title{
ANÁLISE DE PROCESSOS GERENCIAIS NO SETOR DE RAIOS X EM UMA UNIDADE DE PRONTO ATENDIMENTO 24 HORAS DO PARANÁ
}

\author{
A. C. BARCELLOS*, F. S. BARROS* e D. S. SOBOLL* \\ *Universidade Tecnológica Federal do Paraná, Curitiba, Brasil \\ e-mail: atalaha@hotmail.com
}

Resumo: Todas as instituições de saúde do Brasil, públicas ou privadas, são regulamentadas por leis, portarias e resoluções federais, estaduais e municipais. As Unidades de Pronto Atendimento 24 Horas (UPAs), integrantes do Sistema Único de Saúde e regidas pelo governo, devem ser fiscalizadas quanto ao cumprimento dessas normativas visando a proteção e segurança dos pacientes e funcionários. É fundamental, segundo o Conselho Federal de Medicina, que o prontuário (dados de atendimento) seja armazenado corretamente e liberado a terceiros apenas mediante o consentimento do paciente. A ausência de arquivamento das informações, principalmente radiografias, podem ocasionar repetições dos exames e, consequentemente, maior detrimento aos pacientes. O funcionamento preciso dos aparelhos, as condições adequadas das estruturas e o treinamento dos funcionários também garantem maior qualidade de atendimento e proteção a todos os envolvidos. Analisando a existência de inconformidades no setor radiológico de uma UPA em funcionamento há dois anos, em um município do Paraná, de acordo com a legislação predeterminada, foram identificadas as seguintes falhas: uma câmara escura sem iluminação, vedação adequada e sistema de exaustão funcional (exigidos pela Portaria 453/98); um equipamento de raios $\mathrm{x}$ nunca verificado quanto ao seu desempenho; inexistência de um programa de treinamento para os funcionários; arquivamento impróprio de radiografias dos pacientes com sequencial descarte; livro de registros manual sem confirmação de veracidade das informações. Os problemas encontrados no setor geram questionamentos sobre as vistorias realizadas desde a inauguração em 2014 e das habilidades de gestão do órgão responsável pela unidade.

Palavras-chave: Unidade de Pronto Atendimento 24 horas, Setor de Radiologia, Gestão do Setor de Radiologia, Fiscalização do Setor de Radiologia.

Abstract: All brazilian health institutions, public or pri-
vate, are regulated by laws, ordinances and federal,
state and municipal resolutions. The Unidades de
Pronto Atendimento 24 Horas (UPAs), members of the
Sistema Unico de Saude (SUS) and regulated by the
government, should be monitored for compliance of
these regulations aimed at the protection and safety of
patients and staff. It is essential, according to the Con-
selho Federal de Medicina, that the medical record
(treatment data) must be properly stored and released to third parties only with the consent of the patient. The absence of archiving of information, especially X-rays, can cause repetition of the tests and consequently greater detriment to patients. The precise operation of the equipment, the proper conditions of the structures and the training of employees also ensure higher quality of care and protection for all involved. Analyzing the existence of non-conformities in the radiological department of an UPA in operation for two years in a city of Paraná, according to predetermined rules, the following shortcomings were identified: a darkroom without lighting, proper sealing and functional exhaust system (required by Portaria 453/98); an X-ray equipment never checked for its performance; lack of a training program for employees; improper filing of radiographs of patients with sequential discard; book of manual records without confirmation of truthfulness about the information. The problems encountered in the sector generate questions about the inspections conducted since its opening in 2014 and about the management skills of the agency responsible for the unit.

Keywords: Unidades de Pronto Atendimento 24 Horas, Radiology Department, Radiology Sector Management, Supervision of the Radiology Department.

\section{Introdução}

Qualquer estabelecimento de saúde é regido por leis federais, normativas e portarias. Existem legislações e normas para a estrutura, equipamentos, insumos, medicamentos e até mesmo o formato da prestação de serviço, incluindo a necessidade de qualificação dos profissionais e a otimização do atendimento. Todas essas diretrizes protegem o direito do paciente a universalidade, integralidade e equidade no atendimento à saúde, como ditam os princípios do Sistema Único de Saúde (SUS), além de garantir a segurança (tanto física quanto moral) dos profissionais [1]. As resoluções do Conselho Federal de Medicina abordam as ações permitidas por ambos os lados (pacientes e profissionais da saúde) e o não comprimento dos incisos pode gerar processos trabalhistas e criminais.

Gerir todos os processos que envolvem ambientes tão complexos como hospitais e Unidades de Pronto Atendimento (UPA) requer uma equipe multidisciplinar e competente. Stephen L. Grimes, em seu artigo "The Future of Clinical Engineering: The Challenge of Change", relaciona o crescimento da engenharia clínica 
com a exposição de um número relevante de pacientes eletrocutados em procedimentos médicos e, do uso de equipamentos inseguros e perigosos, em relatórios de organizações de saúde norte americanas nos anos 70 [2]. Administrar corretamente a aquisição, instalação, fiscalização, manutenção e descarte de equipamentos se tornou fundamental para garantir a segurança dos pacientes e funcionários, além de consequentemente reduzir custos, dos estabelecimentos assistenciais de saúde (EAS).

As Unidades de Pronto Atendimento $24 \mathrm{~h}$ são instituições públicas integrantes do SUS, entretanto, a dificuldade no repasse de verba suficiente para administrar com eficiência todos os setores não pode isentar a Secretaria Municipal de Saúde da responsabilidade, determinada pelas legislações, sobre falhas de gestão, estruturas deficientes, uso de aparelhos defeituosos e/ou descalibrados, falta de treinamento e condutas profissionais antiéticas. Existe uma grande necessidade de incorporar hábitos organizacionais de prevenção e correção efetiva dos problemas nas unidades de saúde, inclusive nos setores radiológicos, constituídos por equipamentos complexos e caros, e com atribuições essenciais ao diagnóstico dos pacientes.

\section{Materiais e Métodos}

Com o intuito de verificar as inconformidades no setor de radiologia de uma Unidade de Pronto Atendimento 24 Horas, em um município do Estado do Paraná, foram selecionadas leis e normativas referentes ao armazenamento de informação de pacientes (resoluções CFM n ${ }^{\circ} 1.638 / 2002$ [3], CFM n ${ }^{\circ}$ $1.605 / 2000$ [4] e CFM no 1.821/2007 [5]), e aos procedimentos de manutenção e fiscalização principalmente de equipamentos (Portaria n ${ }^{\circ} 453 / 98$ [6]).

Após análise das especificações encontradas em revisão bibliográfica, por método observacional, foram feitos registros documentais e fotográficos da sala de radiografias e câmara escura da UPA. Os resultados fornecem a comparação entre o grau de conformidade exigido por regulamentações nacionais e o encontrado no setor avaliado.

\section{Resultados}

Considerando a importância das informações geradas no atendimento aos pacientes, o Conselho Federal de Medicina fornece especificações acerca do armazenamento desses dados. Conforme a resolução CFM n ${ }^{\circ} 1.638 / 2002$ todas as informações de atendimento prestado ao paciente são responsabilidade não só dos médicos e demais profissionais envolvidos diretamente, mas também das chefias e direção técnica da unidade [3]. Segundo o art. $5^{\circ}$, o prontuário, reunião de dados do indivíduo, deve conter sua identificação, anamnese, exames físicos, exames complementares (como por exemplo: exame de sangue, ultrassonografia, eletrocardiograma, entre outros) com os respectivos laudos, hipóteses de diagnóstico, a definição final do diagnóstico e o tratamento sugerido. $\mathrm{O}$ paciente (e o Conselho Federal/Regional de Medicina), ou seu representante legal, pode requisitar o prontuário a qualquer momento, mas como referido no art. $1^{\mathrm{o}}$ da resolução CFM n ${ }^{\circ} 1.605 / 2000$, sem seu consentimento os dados não podem ser revelados a terceiros [4].

Considerando o desenvolvimento dos sistemas de informações digitais, o conselho autorizou a digitalização dos prontuários, entretanto, em função do art. $7^{\circ}$ da resolução CFM n ${ }^{\circ} 1.821 / 2007$ a obrigação de armazenamento destes dados, pela instituição, se tornou de caráter permanente [5]. Já pelo art. $8^{\circ}$, para os prontuários que não foram arquivados eletronicamente, a guarda foi estabelecida em no mínimo 20 anos, a partir do último registro.

As imagens de radiodiagnóstico, para pacientes internados, são parte integrante do prontuário, já que se encaixam na categoria de exames complementares, e juntamente com as outras informações, são propriedade física da instituição, a quem cabe o dever de armazenamento para que uma cópia autêntica dos dados possa ser entregue ao paciente caso solicitado, como consta na resolução CFM n ${ }^{\circ} 1.821 / 2007$.

Em relação aos equipamentos e a funcionalidade do setor de radiodiagnóstico, a Portaria n ${ }^{\circ} 453 / 98$ do Ministério da Saúde regulamenta os setores de radiodiagnóstico médico e odontológico em relação a proteção dos pacientes e profissionais perante as especificações da realização de exames, as condições físicas do ambiente, as condições funcionais do equipamentos e as competências exigidas dos trabalhadores envolvidos com as técnicas radiológicas [6]. Um dos princípios básicos e primordiais do uso da radiação ionizante para a imaginologia é a Justificação, ou seja, todo exame requisitado pelo médico deve produzir um benefício maior do que o detrimento, já que a radiação ocasiona efeitos biológicos. Qualquer problema no sistema de arquivamento de imagens ou na funcionalidade dos equipamentos pode fazer com que o médico solicite novas radiografias e/ou com que o técnico ache necessário a repetição, gerando maior dose de radiação, ou seja, detrimento para o paciente.

Para que a radiação entregue ao paciente durante o procedimento corresponda com os parâmetros selecionados pelo operador, se faz necessário treinamento da equipe técnica e controle de qualidade dos aparelhos. O item 3.38 indica a obrigatoriedade na implementação de um programa de treinamento anual contemplando os procedimentos de operação dos dispositivos, uso de equipamentos de proteção e monitoração individual e procedimentos para otimização das exposições médicas. Os itens 4.44 e 4.45 da Portaria $n^{\circ} 453$ estabelecem que os equipamentos devem ser mantidos em condições adequadas de funcionamento e verificados frequentemente quanto ao seu desempenho. A classificação de testes subdivide-se em semanalmente, como a sensitometria do sistema de processamento de filmes, semestralmente, como a 
exatidão no sistema de colimação e, anualmente, como a exatidão do indicador de tensão do tubo de raio x $(\mathrm{kVp})$.

A devida vedação do ambiente de processamento de imagens convencionais, o correto armazenamento dos filmes radiográficos que serão utilizados, um sistema de exaustão funcional e uma iluminação adequada na câmara escura (item 4.9 da portaria) também influenciam na qualidade da radiografia. Os artefatos produzidos por más condições ambientais e de revelação dos filmes podem induzir novas realizações de imagens ou falsos diagnósticos.

O setor de radiologia da Unidade de Pronto Atendimento, de um município do Estado do Paraná, é constituído por um equipamento de radiografia convencional da marca Phillips. Tanto o equipamento quanto a própria unidade estão em funcionamento desde 2014, mas até o presente momento não existiram programas de treinamento para orientar os funcionários sobre o funcionamento dos aparelhos ou até mesmo sobre otimização dos exames. A processadora de filmes foi transferida de outra instituição para a unidade, contabilizando muitos anos de uso. Embora exista uma empresa especializada em manutenção corretiva dos dispositivos, apenas a reveladora de radiografias é verificada periodicamente, em função da quebra frequente de peças ou ainda da liberação de filmes úmidos e cheios de sujeira. Em função da inexistência de análises acerca do desempenho do equipamento de raio $x$, não se sabe se os parâmetros selecionados pelo técnico, no painel de controle, estão em conformidade com a emissão de radiação desejada. Em situações como esta, o operador pode precisar aumentar a incidência de raios, e consequentemente a dose no paciente, para compensar falhas técnicas.

Além dos artefatos que são produzidos na revelação das películas pela própria processadora, a câmara escura não conta com vedação apropriada, iluminação específica e funcionamento de exaustor. Por este motivo, os funcionários precisam realizar a função totalmente no escuro e em um ambiente impregnado de vapores químicos. Os filmes armazenados no local também acabam sendo prejudicados pois a umidade é lesiva para seus componentes. A Figura 1 mostra a vedação improvisada na câmara escura.

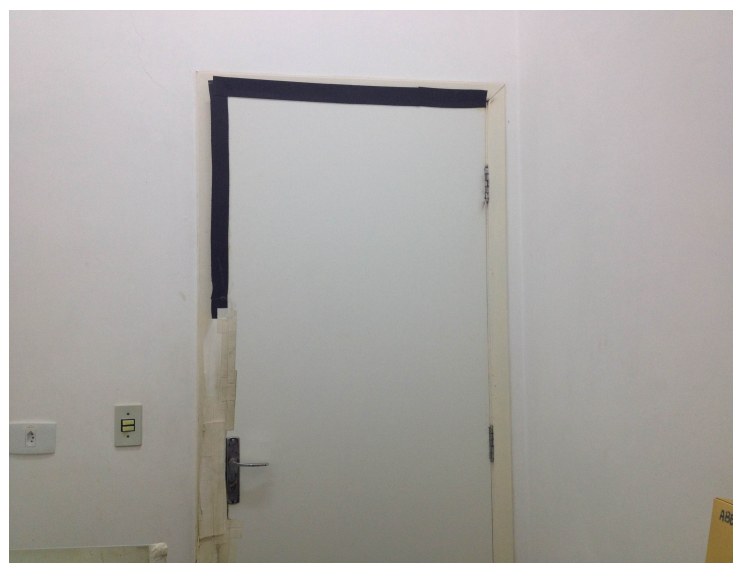

Figura 1: Vedação da porta na parte interna da câmara escura.

As radiografias produzidas no setor são entregues aos pacientes para que retornem ao médico que requisitou o exame e, obtenham o diagnóstico. Legalmente, essas imagens fazem parte do prontuário mas, não são devolvidas aos pacientes, nem digitalizadas (impossibilidade dos aparelhos) e nem arquivadas adequadamente. As imagens são colocados em duas gaveta, juntamente com outros filmes descartados, dificultando a localização se necessária. Quando as gavetas ficam superlotadas, os exames são descartados (uma empresa de rejeitos radioativos faz a coleta). A Figura 2 apresenta a gaveta de armazenamento dos exames.

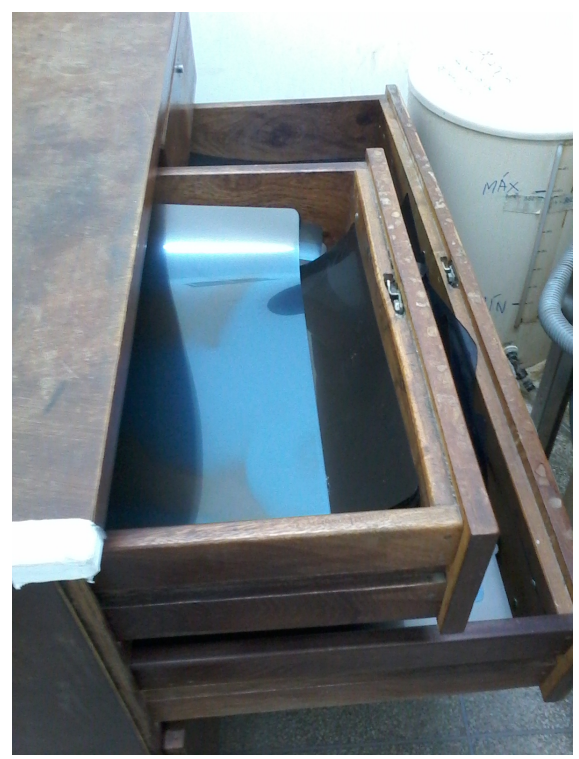

Figura 2: Armazenamento das radiografias de pacientes já analisadas pelos médicos e demais películas descartadas.

\section{Discussão}

Estabelecimentos assistências de saúde são regidos por legislações e normativas, sejam estes públicos ou particulares. Não existe exceções para o não cumprimento dos deveres por uma instituição gerida pelas verbas públicas. A unidade de pronto atendimento de um município do Paraná contém falhas significativas, gerando questionamentos sobre as fiscalizações e vistorias que ocorreram desde sua inauguração até o presente momento.

Os problemas encontrados no setor de radiologia da UPA caracterizam inconsistência de gestão e um certo descaso com os funcionários e pacientes. O arquivamento incoerente, e de curto prazo, das radiografias poderiam gerar processos judiciais além de acréscimo de dose de radiação em repetição de exames desnecessária. Muitos pacientes retornam em menos de uma semana com as mesmas queixas e, a ausência de imagens anteriores gera novas requisições radiológicas. 
A ausência de treinamento e análises de conformidade dos equipamentos do setor de raios $\mathrm{x}$ também contribuem com o acréscimo de dose de radiação, e ainda podem reduzir a qualidade das imagens.

O livro de registros que documenta, de forma manual, os exames realizados, poderia conter dados errôneos que passariam despercebidos, em função da falta de verificação da veracidade das informações. $\mathrm{Ou}$ seja, sem um controle das repetições, o gasto excessivo de filmes (no uso e na compra) e o aumento de irradiações no paciente se torna uma possibilidade.

Todos esses fatores em discordância com as leis predeterminadas acarretam maior detrimento aos pacientes e menor proteção aos funcionários.

\section{Referências}

[1] BRASIL. Lei 8080 de 19 de setembro de 1990. Lei Orgânica da Saúde. Dispõe sobre as condições para promoção, proteção e recuperação da saúde, a organização e o funcionamento dos serviços correspondentes e dá outras providências. Diário da União, Brasília, 1990, Seção 1.

[2] GRIMES S.L., The Future of Clinical Engineering: The Challenge of Change, IEEE Engineering in Medicine and Biology Magazine, p.91-99, mar./apr., 2003.

[3] CONSELHO FEDERAL DE MEDICINA (Brasil). Define prontuário médico e torna obrigatória a criação da Comissão de Revisão de Prontuários nas instituições de saúde. Resolução CFM n ${ }^{\circ}$ 1.638/2002. Publicada no D.O.U. de 9 de agosto de 2002, Seção I, p.184-5

[4] CONSELHO FEDERAL DE MEDICINA (Brasil). O médico não pode, sem o consentimento do paciente, revelar o conteúdo do prontuário ou ficha médica. Revoga-se a Resolução CFM no 999/80. Resolução CFM n ${ }^{\circ} 1.605 / 2000$. Publicada no D.O.U. 29 SET 2000, Seção I, pg. 30

[5] CONSELHO FEDERAL DE MEDICINA (Brasil). Aprova as normas técnicas concernentes a digitalização e uso dos sistemas informatizados para a guarda e manuseio dos documentos dos prontuários dos pacientes, autorizando a eliminação do papel e a troca de informação identificadas em saúde. Resolução CFM n ${ }^{\circ} 1.821 / 2007$. Publicada no D.O.U. de 23 nov. 2007, Seção I, pg. 252.

[6] MINISTÉRIO DA SAÚDE (Brasil). Secretaria de Vigilância Sanitária, Portaria Federal $n^{\circ} 453$, de 01 de junho de 1998: Diretrizes Básicas de Proteção Radiológica em Radiodiagnóstico Médico e Odontológico. Brasília: D.O.U. - Diário Oficial da União; Poder Executivo, de 02 de junho de 1998. 